\title{
Synthesis and Evaluation of Novel Carbocyclic Oxetanocin A (COA-Cl) Derivatives as Potential Tube Formation Agents
}

\author{
Norikazu Sakakibara, ${ }^{*, a}$ Junsuke Igarashi, ${ }^{b}$ Maki Takata ${ }^{c}$ Yosuke Demizu, ${ }^{d}$ Takashi Misawa, ${ }^{d}$ \\ Masaaki Kurihara, ${ }^{d}$ Ryoji Konishi, ${ }^{c}$ Yoshihisa Kato, ${ }^{a}$ Tokumi Maruyama, ${ }^{a}$ and Ikuko Tsukamoto ${ }^{c}$ \\ ${ }^{a}$ Faculty of Pharmaceutical Sciences at Kagawa Campus, Tokushima Bunri University; 1314-1 Shido, Sanuki, \\ Kagawa 769-2193, Japan: ${ }^{b}$ Department of Cardiovascular Physiology, Faculty of Medicine, Kagawa University; \\ 1750-1 Ikenobe, Miki, Kita, Kagawa 761-0793, Japan: ${ }^{c}$ Department of Pharmaco-Bio-Informatics, Faculty of \\ Medicine, Kagawa University; 1750-1 Ikenobe, Miki, Kita, Kagawa 761-0793, Japan: and division of Organic \\ Chemistry, National Institute of Health Sciences; 1-1-18 Kamiyoga, Setagaya-ku, Tokyo 158-8501, Japan. \\ Received May 6, 2015; accepted June 29, 2015
}

Six novel carbocyclic oxetanocin A analogs (2-chloro-C.OXT-A; COA-CI) with various hydroxymethylated or spiro-conjugated cyclobutane rings at the $N^{9}$-position of the 2-chloropurine moiety were synthesized and evaluated using human umbilical vein endothelial cells. All prepared compounds (2a-f) showed good to moderate activity with angiogenic potency. Among these compounds, $100 \mu \mathrm{M}$ cistrans-2',3'-bis(hydroxymethyl)cyclobutyl derivative (2b), trans-3'-hydroxymethylcyclobutyl analog (2d), and $3^{\prime}, 3^{\prime}$-bis(hydroxymethyl)cyclobutyl derivative (2e) had greater angiogenic activity, with relative tube areas of $3.43 \pm 0.44,3.32 \pm 0.53$, and $3.59 \pm 0.83$ (mean \pm standard deviation (S.D.)), respectively, which was comparable to COA-Cl (3.91 \pm 0.78$)$. These data may be important for further development of this class of compounds as potential tube formation agents.

Key words 2-chloro-carbocyclic oxetanocin A; 2-chloro-C.OXT-A; nucleoside derivative; angiogenic activity

Angiogenesis, the process in which new capillary vessels are built from preexisting ones, plays an important role in a variety of situations, including wound healing, tumor growth, and metastasis. Angiogenesis promoters are essential for detecting various symptoms arising due to a lack of blood flow, such as Buerger's disease or chronic arteriosclerosis obliterans in diabetic patients. However, the clinical applications of these promoters as medical agents remain minimal compared to angiogenesis inhibitors, which are utilized as antitumor therapeutics. The lack of angiogenesis promoters used as therapeutic agents may be due to limited knowledge of these promoter, with the exception of growth factors derived from living systems. For example, vascular endothelial growth factor (VEGF) and fibroblast growth factor (FGF) are macromolecular glycoproteins that are chemically and biologically unstable. Hence, they are used only in treatments administered by injection or gene transfection approaches. ${ }^{1-3)}$

We synthesized an angiogenesis promoter 2-chlorocarbocyclic oxetanocin A (COA-Cl), (1a, racemate) (Fig. 1), which is the first low-molecular weight active compound in this class. ${ }^{4-6)}$ The size of compound 1a (molecular weight $(\mathrm{MW})=284)$ is suitable for pharmaceutical use in percutaneous and transmucosal absorption. Therefore, it is expected to have practical applications as a therapeutic for wound healing,
Buerger's disease, or peripheral arterial obliterative disease, and could be developed as an adhesive skin patch, lotion, or oral agent. In addition to its angiogenic effect, we found that $\mathrm{COA}-\mathrm{Cl}$ protects against oxygen-glucose deprivation in primary cortical neurons in a manner sensitive to suramin. ${ }^{7)} \mathrm{Be}$ cause of its utility, $\mathrm{COA}-\mathrm{Cl}$ is commercially available (Chemical Name: 2-Cl-C.OXT-A, WAKENYAKU Co., Ltd., Japan, Order Number: 032-21541, Quantity: 1 mg, Price: 15000 yen).

Our mechanistic studies revealed that the angiogenic effects of $\mathrm{COA}-\mathrm{Cl}$ involves endothelial $\mathrm{S}_{1} \mathrm{P}_{1}$ receptor. $\mathrm{S}_{1} \mathrm{P}_{1}$ receptor is activated by a serum-borne lipid mediator sphingosine 1-phosphate (S1P) as a natural ligand, coupled with G-protein $\alpha \mathrm{i} / \mathrm{o}$ subunit, and is indispensable during normal vascular development. ${ }^{8)}$ Stimulation of $\mathrm{S}_{1} \mathrm{P}_{1}$ by $\mathrm{COA}-\mathrm{Cl}$ activates intracellular signaling pathways, ultimately inducing tube formation in human umbilical vein endothelial cells (HUVECs). ${ }^{9}{ }^{9}$ In agreement with our previous reports, $\mathrm{COA}-\mathrm{Cl}$ promotes the phosphorylation and activation of the mitogen activated protein kinases (MAPK), extracellular signaling-related kinases (ERK1/2), which induce angiogenesis and tube formation, a hallmark of HUVEC angiogenesis. ${ }^{4}$ The ability of $\mathrm{COA}-\mathrm{Cl}$ to modulate ERK1/2 phosphorylation and tube formation is similar to S1P (Fig. 2), the naturally occurring ligand for the $\mathrm{S}_{1} \mathrm{P}_{1}$ receptor. ${ }^{10-12)}$ Thus, these results indicate that $\mathrm{COA}-\mathrm{Cl}$ is a
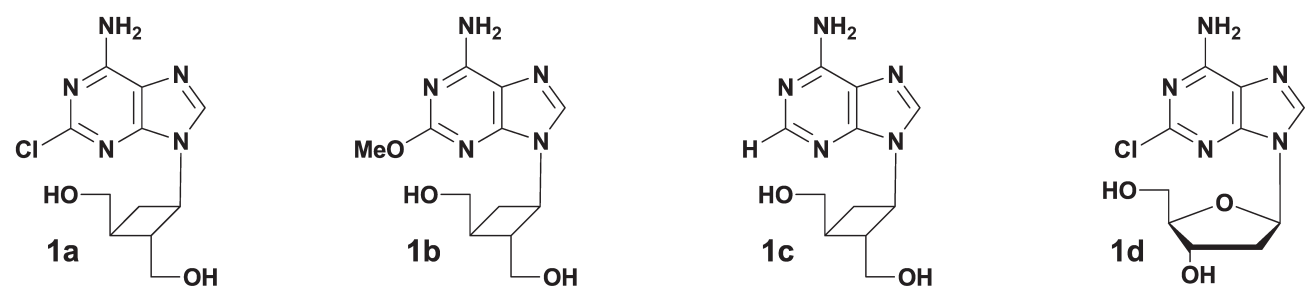

Fig. 1. Structures of COA-Cl (1a), COA-Oe (1b), C.OXT-A (1c), Cladribine (1d) 
<smiles>CCCCCCCCCCCCC/C=C/[C@@H](O)[C@H](N)COP(=O)(O)O</smiles>

S1P<smiles>NC(CO)(CO)CCc1ccc(Sc2cccc(OCc3ccccc3)c2)cc1Cl</smiles>

KRP-203<smiles>[R6]CC(N)(CO)CCc1ccc(CCCCCCCC)cc1</smiles>

R = H: FTY -720

$\mathrm{R}=\mathrm{PO}_{3} \mathrm{H}_{2}:$ FTY-720-P

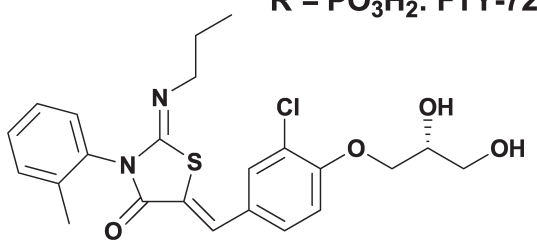

ACT-128800

Fig. 2. Structures of S1P, FTY-720, FTY-720-P, KRP-203, and ACT-128800
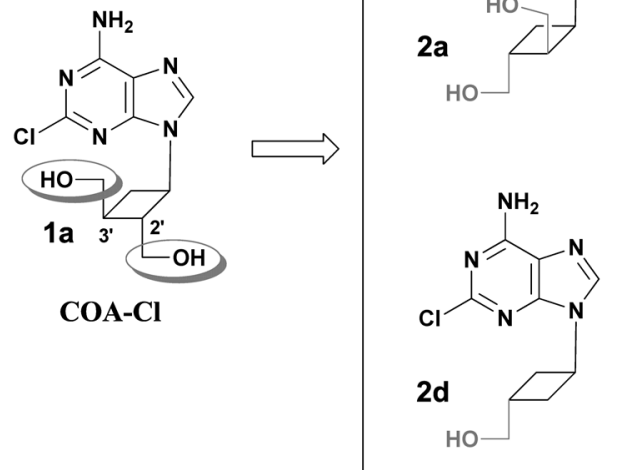

Fig. 3. Structures of COA-Cl (1) and COA-Cl Analogs (2a-f)

novel and potent angiogenic agent that may behave as a partial agonist of the $\mathrm{S}_{1} \mathrm{P}_{1}$ receptor.

Several S1P derivatives have been developed as $\mathrm{S}_{\mathrm{P}}$ agonists, including FTY-720, ${ }^{13,14)}$ FTY-720-P, ${ }^{13,14)}$ KRP-203, ${ }^{15)}$ and ACT- $128800^{16)}$ (Fig. 2). These compounds can block the egress of T cells from the thymus and lymphoid organs, ${ }^{17,18)}$ and may be promising oral therapeutics for autoimmune disorders. Nevertheless, outside of COA-Cl 1a, no other compound has been shown to exert neovascularization effects via the $\mathrm{S}_{1} \mathrm{P}_{1}$ receptor. Thus, $\mathrm{COA}-\mathrm{Cl}$ has the potential for clinical applications as an angiogenic medicine acting via the $\mathrm{S}_{1} \mathrm{P}_{1}$ receptor.

Understanding of the unique mechanism of $\mathrm{COA}-\mathrm{Cl} \mathbf{1 a}$ has triggered intensive effort to discover $\mathrm{COA}-\mathrm{Cl}$ analogs with enhanced angiogenic activity and reduced cytotoxicity., ${ }^{4,6}$ However, our previous work has resulted in analogs with no or less potency to $\mathrm{COA}-\mathrm{Cl}$ 1a. For example, the COA-Cl derivative, $\mathrm{COA}-\mathrm{OMe}(\mathbf{1 b})$, in which the 2-chloro group at the 2-position in the purine system is substituted with a methoxy group (Fig. 1), displayed half the vascularization activity of COA-Cl 1a. ${ }^{6}$ Furthermore, substitution of an $\mathrm{H}$ in place of the $\mathrm{Cl}$ (1c: C.OXT-A) or replacement of a cyclobutane moiety with the pentose ring (1d: cladribine, used to treat hairy cell leukemia and multiple sclerosis) showed no angiogenic potency. ${ }^{4)}$ Collectively, these studies indicated that the structure of the 2-chloropurine skeleton and the cyclobutane ring moiety in
COA-Cl 1a was essential for its angiogenic activity. Nevertheless, the role of the two hydroxymethyl groups bound to the cyclobutane ring at the $2^{\prime}$ and $3^{\prime}$ position remain unclear.

In the present study, we sought to further elucidate the angiogenic function of hydroxymethyl group(s) on COA-Cl 1a. More specifically, six novel $\mathrm{COA}-\mathrm{Cl}$ analogs racemates $\mathbf{2 a}$, b, and achiral compounds 2c-f (Fig. 3) with a variety of hydroxymethylated or spiro-conjugated cyclobutane rings at the $N^{9}$-position in the 2-chloropurine moiety were synthesized and evaluated in HUVECs.

\section{Results and Discussion}

Chemistry The COA-Cl analogs $\mathbf{2 a}-\mathbf{d}$ shown in Chart 1 were prepared using known cyclobutyl alcohols $\left(\mathbf{3 a},{ }^{19)} \mathbf{b},{ }^{20)}\right.$ $\mathbf{c}^{21,22)} \mathbf{d},{ }^{21,23)}$ ) as starting materials in two steps reactions, according to a modified method from a previous report. ${ }^{24)}$ Secondary alcohols 3a-d were treated with 2,6-dichloropurine and underwent the Mitsunobu reaction ${ }^{25}$ in the presence of $\mathrm{PPh}_{3}$ and DIAD to yield 9-cyclobutyl-2,6-dichloropurine congeners, $\mathbf{4 a - d}$, in $37-84 \%$ yields, which were treated with methanolic ammonia to give the desired products $\mathbf{2 a - d}$ in $68-87 \%$ yields.

The relative configurations of $\mathbf{4 b} \mathbf{b}-\mathbf{d}$ were determined on the basis of nuclear Overhauser effect spectroscopy (NOESY) correlations (Fig. 4) and comparison with previous litera- 

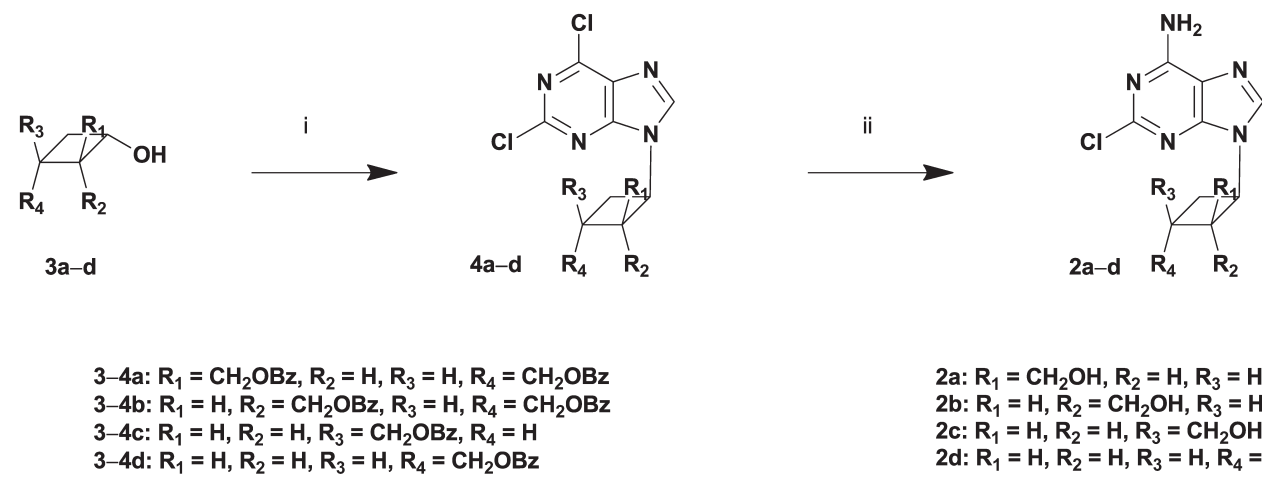

Reagents and conditions: i, 2,6-Dichloropurine, $\mathrm{PPh}_{3}$, DIAD, THF, $50^{\circ} \mathrm{C}$; ii, $\mathrm{NH}_{3}, \mathrm{MeOH}, 100^{\circ} \mathrm{C}$.

Chart 1. Synthesis of Compounds $\mathbf{2 a - d}$
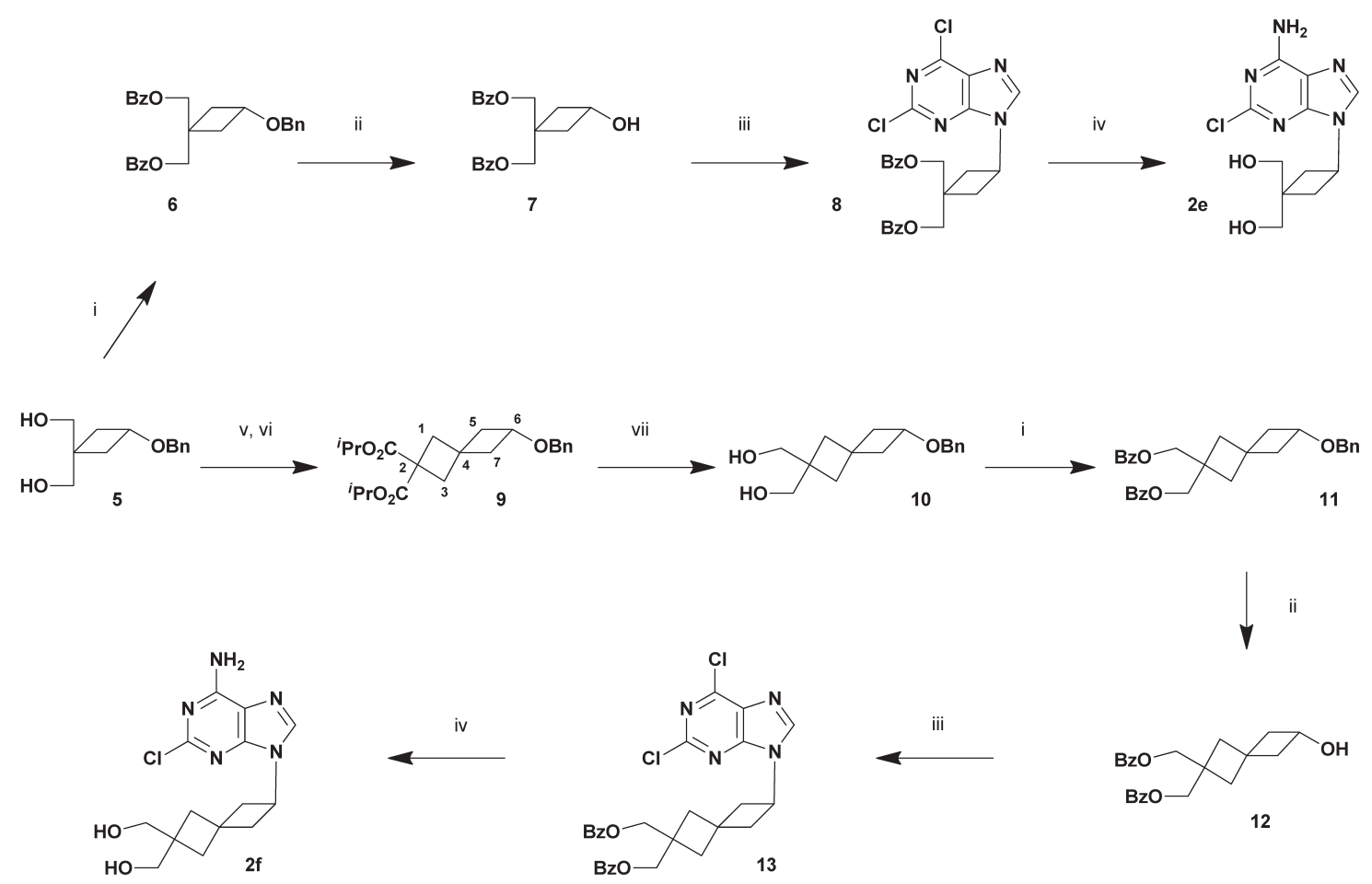

Reagents and conditions: i, BzCl, Pyridine, rt; ii, Pd/C, $\mathrm{H}_{2}$, rt; iii, 2,6-Dichloropurine, $\mathrm{PPh}_{3}$, DIAD, THF, $50^{\circ} \mathrm{C}$; iv, $\mathrm{NH}_{3}, \mathrm{MeOH}, 100^{\circ} \mathrm{C}$; v, TsCl, Pyridine, rt; vi, $\mathrm{NaH}$, Dimethylmalonate, toluene, reflux; vii, $\mathrm{LiAlH}_{4}, \mathrm{THF},-20^{\circ} \mathrm{C}$.

Chart 2. Synthesis of Compounds $2 \mathbf{e}$ and $\mathbf{f}$
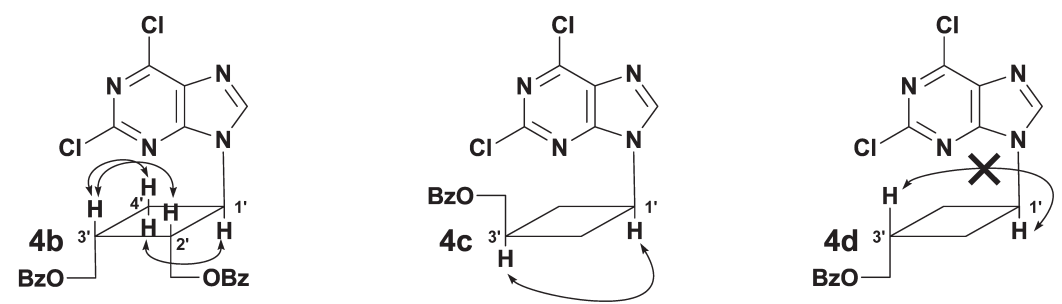

Fig. 4. Key NOESY $(\mathrm{H} \leftrightarrow \mathrm{H})$ Correlations and Relative Configuration of Compounds $\mathbf{4} \mathbf{b}-\mathbf{d}$

ture. $^{20-23)}$ For compound $\mathbf{4 b}$, the NOESY correlations between $\mathrm{H}-\mathrm{1}^{\prime}$ and $\mathrm{H}-4^{\prime} \mathrm{b}$, between $\mathrm{H}-4^{\prime} \mathrm{a}$ and $\mathrm{H}-3^{\prime}$, and between $\mathrm{H}-2^{\prime}$ and $\mathrm{H}-3^{\prime}$, and the absence of NOESY correlations between $\mathrm{H}-1^{\prime}$ and $\mathrm{H}-2^{\prime}$, suggested the $1^{\prime}, 2^{\prime}$-trans-2',3'-cis congener (4b). Similarly, for compounds $\mathbf{4 c}$ and $\mathbf{d}$, the NOESY correlations between $\mathrm{H}-\mathrm{1}^{\prime}$ and $\mathrm{H}-3^{\prime}$ indicated the $1^{\prime}, 3^{\prime}$-cis analog (4c), whereas the absence of NOESY correlations between $\mathrm{H}-\mathrm{l}^{\prime}$ and
H-3' indicated the 1',3'-trans derivative (4d).

The synthesis of $\mathrm{COA}-\mathrm{Cl}$ derivatives $\mathbf{2 e}$ and $\mathbf{f}$ is described in Chart 2. Starting from 3,3-bis(hydroxymethyl)-1-benzyloxycyclobutane $5{ }^{26)}$ we prepared dibenzoyl ester $\mathbf{6}$ in a $90 \%$ yield, followed by debenzylation with palladium carbon $(\mathrm{Pd}-\mathrm{C}) / \mathrm{H}_{2}$ to afford alcohol 7 in $91 \%$ yield. Compound 7 was then condensed with 2,6-dichloropurine using the Mitsu- 


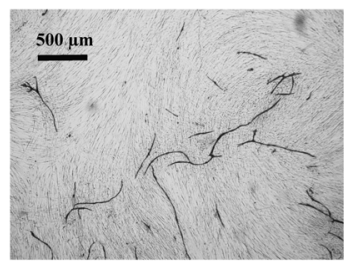

solvent (saline 10\%)

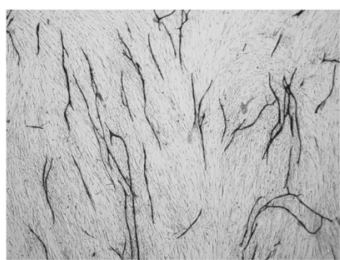

Compound 2a $100 \mu \mathrm{M}$

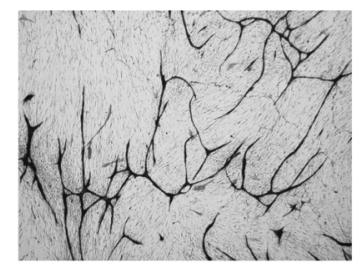

Compound 2d $100 \mu \mathrm{M}$

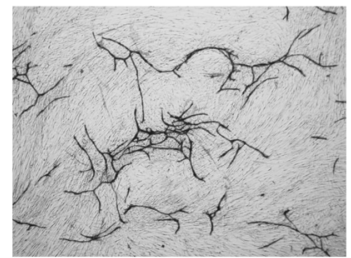

VEGF $10 \mathrm{ng} / \mathrm{mL}$

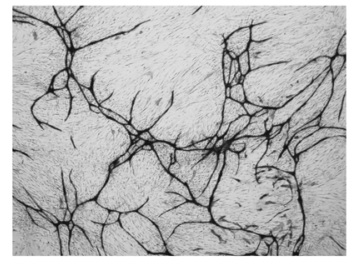

Compound 2b $100 \mu \mathrm{M}$

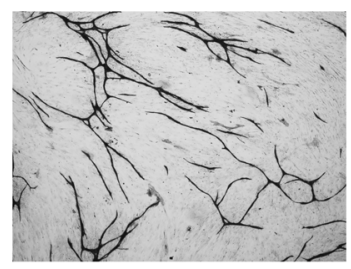

Compound 2e $100 \mu \mathrm{M}$

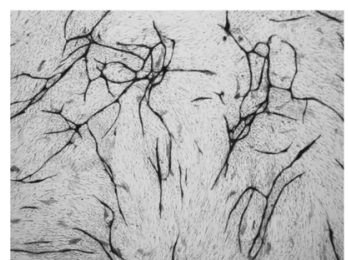

COA-Cl 1a $100 \mu \mathrm{M}$

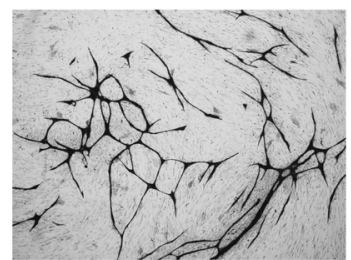

Compound 2c $100 \mu \mathrm{M}$

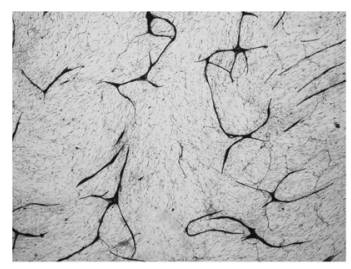

Compound 2f $100 \mu \mathrm{M}$

Fig. 5. Pictures of Stimulated Tube Formation by $\mathbf{1 a}$ and $\mathbf{2 a}-\mathbf{f}$

Additives are shown under the pictures.

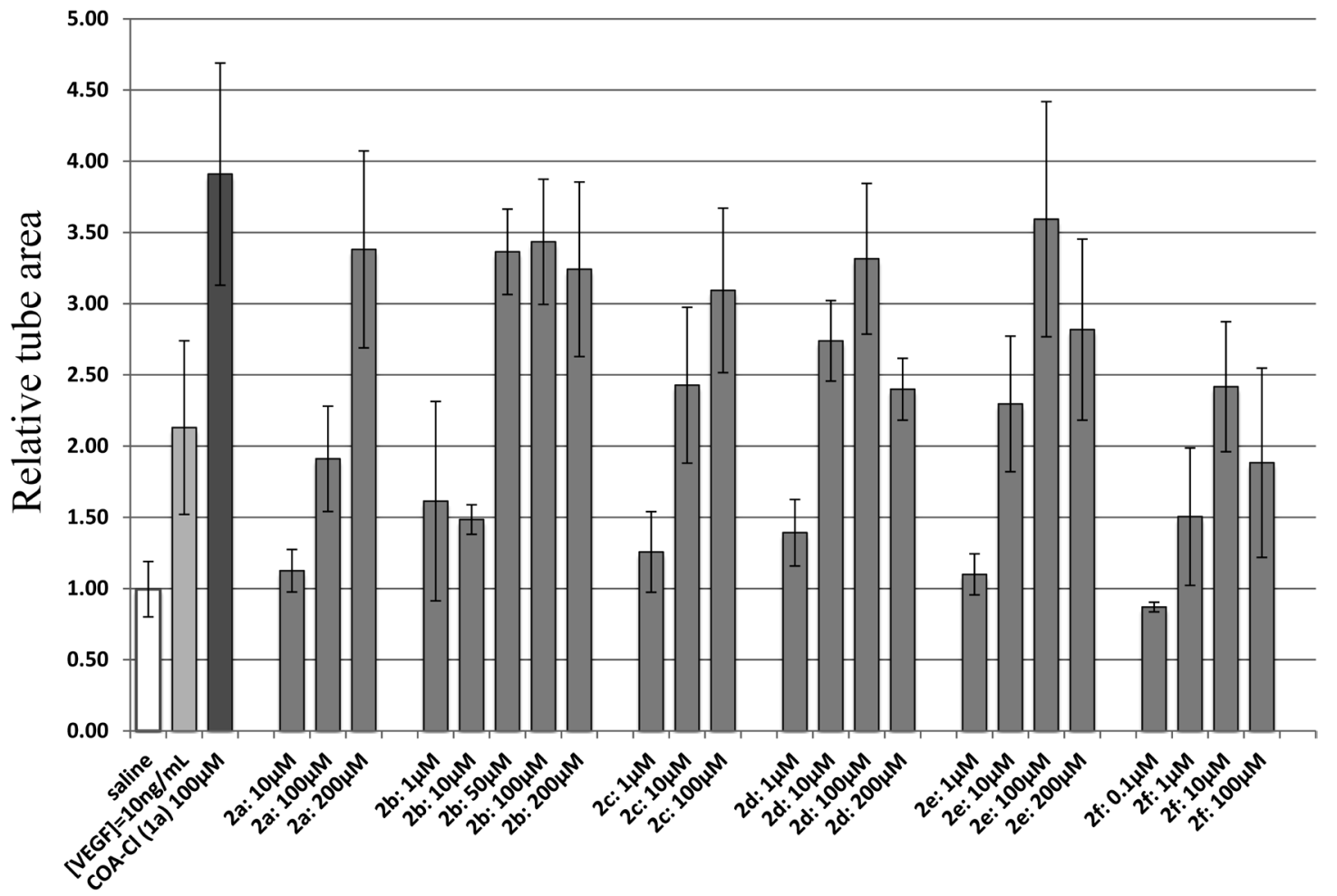

Fig. 6. Tube Formation Assay Using Compounds 1a and 2a-f

The tube formation assay was performed using an angiogenesis kit, and the estimation was performed $10 \mathrm{~d}$ after incubation with the designated compounds. The area of the formed tube was represented as a relative value versus control wells with no additives. The effect of the solvent (10\% saline) and positive control (VEGF; 10 ng/mL) are shown together. Results were expressed as mean \pm S.E. of 2-6 individual experiments.

nobu reaction ${ }^{25}$ to afford $\mathbf{8}$ in a $75 \%$ yield, which was treated with methanolic ammonia to give the desired product $2 \mathbf{e}$ in a $50 \%$ yield. As for the preparation of spiro-counterpart $\mathbf{2 f}$, compound $\mathbf{5}$ was transformed into its (bis)tosyl derivative, which in turn was alkylated by diisopropylmalonate to form diisopropyl dicarboxylated product 9 in an $87 \%$ yield, possessing the spiro[3.3] heptane core. ${ }^{27)}$ The resulting product 9 was reduced with $\mathrm{LiAlH}_{4}$ to afford diol $\mathbf{1 0}$ in a $34 \%$ yield, 


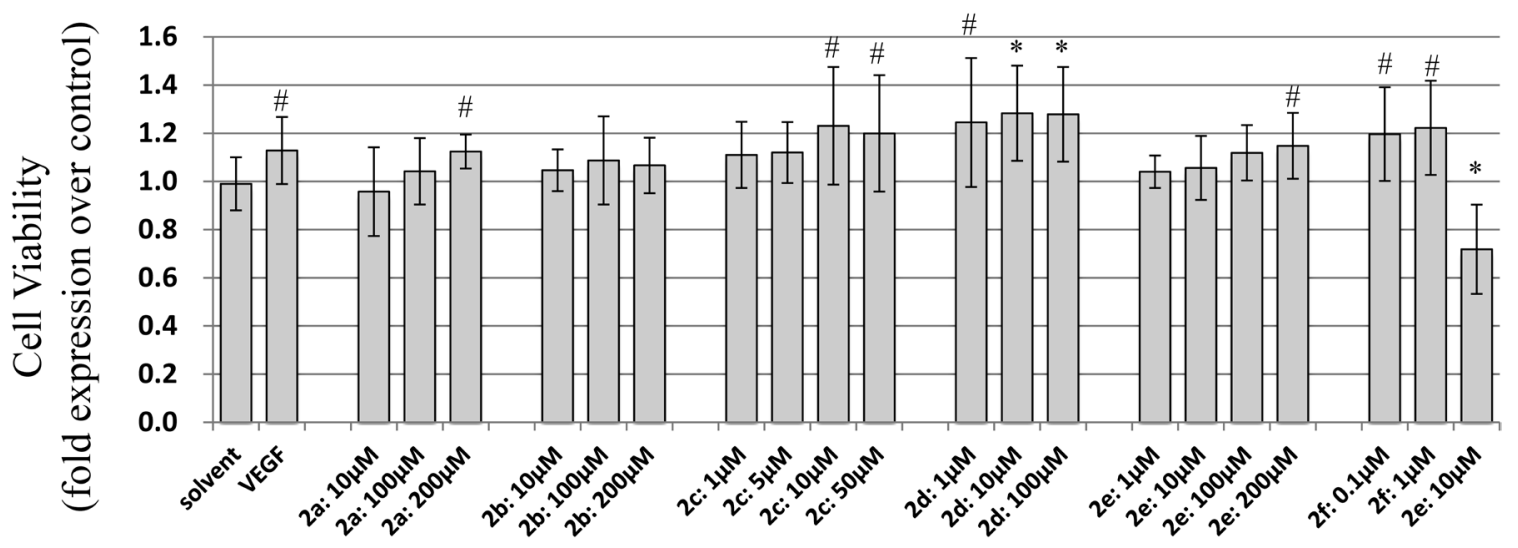

Fig. 7. Effect of Compounds $\mathbf{2 a - f}$ on the Proliferation

Forty-eight hours after the addition of additives, the cell viability was measured with a Cell Counting Kit- 8 . Cell viabilities were represented as relative values to that of the control well with no additive. The effect of the solvent, $10 \%$ saline as well as a positive control, VEGF (10 ng/mL) were shown together. Results were expressed as mean \pm S.E. of more than four individual experiments. ${ }^{*} p<0.01$ and ${ }^{*} p<0.05 v s$. solvent (by Student's $t$-test).

which was subsequently acylated with benzoyl chloride to yield dibenzoyl ester $\mathbf{1 1}$ in an $87 \%$ yield. Compound $\mathbf{1 1}$ was hydrogenated with $\mathrm{Pd}-\mathrm{C}$ to produce secondary alcohol $\mathbf{1 2}$ in a $72 \%$ yield, followed by the Mitsunobu reaction ${ }^{25}$ ) to provide the spiro-condensation product $\mathbf{1 3}$ in an $86 \%$ yield, which was treated with methanolic ammonia to give the objective spirodiol $2 \mathbf{f}$ in a $70 \%$ yield.

Biological Activity The effects of the synthesized nucleoside analogs (2a-f) on angiogenesis were examined. We evaluated the analogs using a well-established tube formation assay. ${ }^{4,28,29)}$ All experiments were performed 2-6 times. Ten days following the incubation of the fibroblasts and additives, HUVECs were stained using the Tubule Staining Kit for CD31. Typical pictures are shown in Fig. 5. VEGF was used as a positive control. The area of the formed tube was represented as a relative value to tubes formed in wells without additives (saline). Figure 6 shows the dose-dependent tube formation responses, as well as the solvent control (10\% saline) and positive control (VEGF, $10 \mathrm{ng} / \mathrm{mL}$ ).

As shown in Figs. 5 and 6, angiogenic potencies were observed in every prepared compound, including the cistrans-2',3'-bis(hydroxymethyl)cyclobutyl derivative, 2a, cistrans-2',3'-bis(hydroxymethyl)cyclobutyl derivative, $\mathbf{2 b}$, cis3'-hydroxymethylcyclobutyl derivative, 2c, trans-3'-hydroxymethylcyclobutyl derivative, 2d, 3',3'-bis(hydroxymethyl)cyclobutyl derivative 2e, and $2^{\prime}, 2^{\prime}$-bis(benzoyloxymethyl)spiro[3'.3']hept-6'-yl derivative 2 f (Fig. 3). Among these, at a concentration of $100 \mu \mathrm{M}, \mathbf{2} \mathbf{b}, \mathbf{d}$, and exerted greater angiogenic activity $(3.43 \pm 0.44,3.32 \pm 0.53$, and $3.59 \pm 0.83$ [mean \pm standard deviation (S.D.)], respectively) which was comparable to $\mathrm{COA}-\mathrm{Cl}$ 1a $(3.91 \pm 0.78)$. Compound 2d was most angiogenic when using $10 \mu \mathrm{M}(2.74 \pm 0.28)$, which was superior to the potency of COA-Cl $1 \mathrm{a}(2.44 \pm 0.89$ at $10 \mu \mathrm{M})$ in our previous report ${ }^{4)}$ and $10 \mathrm{ng} / \mathrm{mL}$ VEGF (2.13 \pm 0.61$)$. Surprisingly, the angiogenic activity of spiro analog $2 \mathbf{f}$ at $10 \mu \mathrm{M}$ was $2.42 \pm 0.46$, which was nearly identical to that of $1 \mathbf{a}$ at same concentration. The potency of $\mathbf{2} \mathbf{d}-\mathbf{f}$ reached a maximum around $10-100 \mu \mathrm{M}$, and decreased at $100-200 \mu \mathrm{M}$, indicating that the cellular proliferation was eventually inhibited at a high analog concentration.

Moreover, as shown in Fig. 7, we performed a proliferation assay because angiogenesis is intimately associated with com- plex cellular processes, including proliferation of endothelial cells, ${ }^{4,28,29)}$ which showed that compounds $\mathbf{2 a - f}$ promoted the proliferation of HUVECs at a higher concentration (e.g., 2a: $200 \mu \mathrm{M}: 1.12 \pm 0.07, n=5, p=0.031)$, whereas $2 \mathrm{f}$ at a concentration of $10 \mu \mathrm{M}$ only inhibited the proliferation of HUVECs $(0.72 \pm 0.19, n=5, p=0.005)$.

\section{Conclusion}

In the present study, a series of newly synthesized COA-Cl analogs exhibited good to moderate angiogenic activity. In particular, $100 \mu \mathrm{m}$ of the COA-Cl analogs, $\mathbf{2} \mathbf{b}, \mathbf{d}$, and e induced enhanced angiogenesis, with relative tube areas of $3.43 \pm 0.44$, $3.32 \pm 0.53$, and $3.59 \pm 0.83$, respectively. This was comparable with the tube area induced by $\mathrm{COA}-\mathrm{Cl}(3.91 \pm 0.78)$. Overall, our data may serve as the basis for further modification to identify more potent candidates to induce tube formation.

\section{Experimental}

Chemistry ${ }^{1} \mathrm{H}-\mathrm{NMR}$ and ${ }^{13} \mathrm{C}-\mathrm{NMR}$ spectra were taken with a Ultrashield ${ }^{\mathrm{TM}} 400$ Plus FT NMR System (BRUKER). Chemical shifts and coupling constants $(J)$ were given in $\delta$ and $\mathrm{Hz}$, respectively. Melting points were determined on a Yanaco MP-500D. High-resolution mass spectrometry was performed on a APEX IV mass spectrometer (BRUKER) with electrospray ionization mass spectroscopy (ESI-MS).

General Procedure for the Synthesis of 4a-d A solution of compound $\mathbf{3 a}-\mathbf{d}(0.38 \mathrm{mmol})$, triphenylphosphine (104.9 mg, $0.40 \mathrm{mmol}), 2,6$-dichloropurine $(75.4 \mathrm{mg}, 0.40 \mathrm{mmol})$ and DIAD (diisopropyl azodicarbosylate, $78.8 \mu \mathrm{L}, 0.40 \mathrm{mmol}$ ) in tetrahydrofuran (THF) $(3.0 \mathrm{~mL})$ was stirred at $50^{\circ} \mathrm{C}$. After $8-15 \mathrm{~h}$ stirring, the residual solution was purified by silica gel column chromatography (60\% AcOEt in hexane) to give $\mathbf{4 a - d}$.

2,6-Dichloro-9-[cis-trans-2',3'-bis(benzoyloxymethyl)cyclobutyl]purine (4a)

Yield 37\%; oil; ${ }^{1} \mathrm{H}-\mathrm{NMR}\left(400 \mathrm{MHz}, \mathrm{CDCl}_{3}\right) \delta$ : $8.34(1 \mathrm{H}$, $\mathrm{s}, \mathrm{H}-8), 8.06-8.12(2 \mathrm{H}, \mathrm{m}, \mathrm{Bz}), 7.45-7.64(6 \mathrm{H}, \mathrm{m}, \mathrm{Bz})$, 7.31-7.38 (2H, m, Bz), $5.52\left(1 \mathrm{H}, \mathrm{m}, \mathrm{H}-1^{\prime}\right), 4.53-4.66(2 \mathrm{H}, \mathrm{m}$, $\left.3^{\prime}-\underline{\mathrm{CH}}_{2} \mathrm{OBz}\right), 4.30-4.41\left(2 \mathrm{H}, \mathrm{m}, 2^{\prime}-\underline{\mathrm{CH}}_{2} \mathrm{OBz}\right), 3.42(1 \mathrm{H}, \mathrm{m}$, $\left.\mathrm{H}-2^{\prime}\right), 3.20\left(1 \mathrm{H}, \mathrm{m}, \mathrm{H}-4^{\prime} \mathrm{a}\right), 2.96\left(1 \mathrm{H}, \mathrm{m}, \mathrm{H}-3^{\prime}\right), 2.76(1 \mathrm{H}, \mathrm{m}$, $\left.\mathrm{H}-4{ }^{\prime} \mathrm{b}\right) ;{ }^{13} \mathrm{C}-\mathrm{NMR}\left(100 \mathrm{MHz}, \mathrm{CDCl}_{3}\right) \delta: 166.4,165.5,153.4$, $153.0,151.8,144.2,144.2,133.4,133.4,131.0,129.6,129.0$, $128.7,128.6,128.5,65.9,62.4,48.8,41.4,32.3,26.9$; high reso- 
lution (HR)-MS (ESI) Calcd for $\mathrm{C}_{25} \mathrm{H}_{20} \mathrm{Cl}_{2} \mathrm{~N}_{4} \mathrm{NaO}_{4}[\mathrm{M}+\mathrm{Na}]^{+}$: 533.07538. Found 533.0713.

2,6-Dichloro-9-[trans-cis-2',3'-bis(benzoyloxymethyl)cyclobutyl]purine (4b)

Yield 38\%; white crystals; ${ }^{1} \mathrm{H}-\mathrm{NMR}\left(400 \mathrm{MHz}, \mathrm{CDCl}_{3}\right) \delta$ : 8.28 (1H, s, H-8), 8.08 (2H, m, Bz), 7.69 (2H, m, Bz), 7.30-7.63 $(6 \mathrm{H}, \mathrm{m}, \mathrm{Bz}), 5.25\left(1 \mathrm{H}, \mathrm{m}, \mathrm{H}-1^{\prime}\right), 4.52-4.75\left(4 \mathrm{H}, \mathrm{m}, 2^{\prime}-\mathrm{CH}_{2} \mathrm{OBz}\right.$ and $\left.3^{\prime}-\mathrm{CH}_{2} \mathrm{OBz}\right), 3.73\left(1 \mathrm{H}, \mathrm{m}, \mathrm{H}-2^{\prime}\right), 3.17\left(1 \mathrm{H}, \mathrm{m}, \mathrm{H}-3^{\prime}\right), 2.99$ (1H, m, H-4'a), 2.58 (1H, m, H-4'b); ${ }^{13} \mathrm{C}-\mathrm{NMR}(100 \mathrm{MHz}$, $\left.\mathrm{CDCl}_{3}\right) \delta: 166.3,166.2,152.9,152.8,151.8,144.4,133.4,133.4$, 131.1, 129.6, 129.6, 129.2, 129.0, 128.6, 128.4, 64.0, 63.1, 51.5, 43.4, 30.2, 29.2; HR-MS (ESI) Calcd for $\mathrm{C}_{25} \mathrm{H}_{20} \mathrm{Cl}_{2} \mathrm{~N}_{4} \mathrm{NaO}_{4}$ $[\mathrm{M}+\mathrm{Na}]^{+}:$533.07538. Found 533.07531; mp: $57.5-58.5^{\circ} \mathrm{C}$.

2,6-Dichloro-9-(cis-3'-benzoyloxymethylcyclobutyl)purine (4c)

Yield 62\%; white crystals; ${ }^{1} \mathrm{H}-\mathrm{NMR}\left(400 \mathrm{MHz}, \mathrm{CDCl}_{3}\right)$ $\delta: 8.20(1 \mathrm{H}, \mathrm{s}, \mathrm{H}-8), 8.05(2 \mathrm{H}, \mathrm{m}, \mathrm{Bz}), 7.59(1 \mathrm{H}, \mathrm{m}, \mathrm{Bz})$, $7.47(2 \mathrm{H}, \mathrm{m}, \mathrm{Bz}), 5.00\left(1 \mathrm{H}, \mathrm{m}, \mathrm{H}-1^{\prime}\right), 4.47(2 \mathrm{H}, \mathrm{d}, J=5.2 \mathrm{~Hz}$, $\left.3^{\prime}-\mathrm{CH}_{2} \mathrm{OBz}\right), 2.85\left(2 \mathrm{H}, \mathrm{m}, \mathrm{H}-2^{\prime} \mathrm{a}\right.$ and $\left.\mathrm{H}-4^{\prime} \mathrm{a}\right), 2.75(1 \mathrm{H}, \mathrm{m}$, $\left.\mathrm{H}-3^{\prime}\right), 2.60\left(2 \mathrm{H}, \mathrm{m}, \mathrm{H}-2^{\prime} \mathrm{b}\right.$ and $\left.\mathrm{H}-4^{\prime} \mathrm{b}\right) ;{ }^{13} \mathrm{C}-\mathrm{NMR}(100 \mathrm{MHz}$, $\left.\mathrm{CDCl}_{3}\right) \delta: 166.5,152.9,152.8,151.8,144.1,133.3,129.9,129.5$, 129.5, 128.6, 128.6, 66.8, 46.1, 33.1, 28.0; HR-MS (ESI) Calcd for $\mathrm{C}_{17} \mathrm{H}_{14} \mathrm{Cl}_{2} \mathrm{~N}_{4} \mathrm{NaO}_{2}[\mathrm{M}+\mathrm{Na}]^{+}$: 399.03860. Found 399.03772; mp: $164.2-165.6^{\circ} \mathrm{C}$.

2,6-Dichloro-9-(trans-3'-benzoyloxymethylcyclobutyl)purine (4d)

Yield 84\%; white crystals; ${ }^{1} \mathrm{H}-\mathrm{NMR}\left(400 \mathrm{MHz}, \mathrm{CDCl}_{3}\right)$ $\delta$ : $8.25(1 \mathrm{H}, \mathrm{s}, \mathrm{H}-8), 8.10(2 \mathrm{H}, \mathrm{m}, \mathrm{Bz}), 7.61(1 \mathrm{H}, \mathrm{m}, \mathrm{Bz})$, $7.49(2 \mathrm{H}, \mathrm{m}, \mathrm{Bz}), 5.30\left(1 \mathrm{H}, \mathrm{m}, \mathrm{H}-1^{\prime}\right), 4.54(2 \mathrm{H}, \mathrm{d}, J=6.4 \mathrm{~Hz}$, $\left.3^{\prime}-\mathrm{CH}_{2} \mathrm{OBz}\right), 3.04\left(1 \mathrm{H}, \mathrm{m}, \mathrm{H}-3^{\prime}\right), 2.91\left(2 \mathrm{H}, \mathrm{m}, \mathrm{H}-2^{\prime} \mathrm{a}\right.$ and $\left.\mathrm{H}-4^{\prime} \mathrm{a}\right), 2.70\left(2 \mathrm{H}, \mathrm{m}, \mathrm{H}-2^{\prime} \mathrm{b}\right.$ and $\left.\mathrm{H}_{-} 4^{\prime} \mathrm{b}\right) ;{ }^{13} \mathrm{C}-\mathrm{NMR}(100 \mathrm{MHz}$, $\left.\mathrm{CDCl}_{3}\right) \delta: 166.6,153.0,152.9,151.9,144.2,133.3,131.2,129.9$, 129.6, 128.6, 66.7, 48.1, 31.8, 28.3; HR-MS (ESI) Calcd for $\mathrm{C}_{17} \mathrm{H}_{14} \mathrm{Cl}_{2} \mathrm{~N}_{4} \mathrm{NaO}_{2}[\mathrm{M}+\mathrm{Na}]^{+}:$399.03860. Found 399.03753; mp: 147.7-149.5 ${ }^{\circ} \mathrm{C}$.

General Procedure for the Synthesis of $2 \mathbf{a}-\mathbf{d}$ Compounds $4 \mathbf{a}-\mathbf{d}(0.12 \mathrm{mmol})$ was dissolved in $\mathrm{NH}_{3}(14.0 \mathrm{~mL}) /$ $\mathrm{MeOH}(3.0 \mathrm{~mL})$, and then sealed and stirred for $1-3 \mathrm{~d}$ at $100^{\circ} \mathrm{C}$. The mixture was evaporated, and the residue was purified by silica gel column chromatography $(20-25 \% \mathrm{MeOH}$ in $\mathrm{CH}_{2} \mathrm{Cl}_{2}$ ) to afford $\mathbf{2} \mathbf{a}-\mathbf{d}$.

2-Amino-6-chloro-9-[cis-trans-2',3'-bis(hydroxymethyl)cyclobutyl]purine (2a)

Yield 84\%; white crystals; ${ }^{1} \mathrm{H}-\mathrm{NMR}\left(400 \mathrm{MHz}, \mathrm{CDCl}_{3}\right) \delta$ : $8.36(1 \mathrm{H}, \mathrm{s}, \mathrm{H}-8), 7.70(2 \mathrm{H}$, brs, 6-NH $), 5.07\left(1 \mathrm{H}, \mathrm{m}, \mathrm{H}-1^{\prime}\right)$, $4.75\left(1 \mathrm{H}, \mathrm{t}, J=4.8 \mathrm{~Hz}, 3^{\prime}-\mathrm{OH}\right), 4.30\left(1 \mathrm{H}, \mathrm{t}, J=5.2 \mathrm{~Hz}, 2^{\prime}-\mathrm{OH}\right)$, $3.56\left(2 \mathrm{H}, \mathrm{m}, 3^{\prime}-\mathrm{CH}_{2} \mathrm{OBz}\right), 3.31\left(2 \mathrm{H}, \mathrm{m}, 2^{\prime}-\mathrm{CH}_{2} \mathrm{OBz}\right), 2.90$ (1H, m, H-4'a), 2.58 (1H, m, H-2'), 2.33 (1H, m, H-4'b), 2.30 $\left(1 \mathrm{H}, \mathrm{m}, \mathrm{H}-3^{\prime}\right) ;{ }^{13} \mathrm{C}-\mathrm{NMR}\left(100 \mathrm{MHz}, \mathrm{CDCl}_{3}\right) \delta$ : 158.0, 155.1, 152.6, 142.2, 119.1, 65.4, 61.6, 50.0, 45.4, 36.5, 27.8; HR-MS (ESI) Calcd for $\mathrm{C}_{11} \mathrm{H}_{14} \mathrm{ClN}_{5} \mathrm{NaO}_{2}[\mathrm{M}+\mathrm{Na}]^{+}: 306.07282$. Found 306.07162; mp: $226.5-227.7^{\circ} \mathrm{C}$.

2-Amino-6-chloro-9-[trans-cis-2',3'-bis(hydroxymethyl)cyclobutyl]purine (2b)

Yield 87\%; white crystals; ${ }^{1} \mathrm{H}-\mathrm{NMR}\left(400 \mathrm{MHz}, \mathrm{CD}_{3} \mathrm{OD}\right)$ $\delta$ : $8.14(1 \mathrm{H}, \mathrm{s}, \mathrm{H}-8), 4.80\left(1 \mathrm{H}, \mathrm{m}, \mathrm{H}-1^{\prime}\right), 3.65-3.80(4 \mathrm{H}, \mathrm{m}$, $2^{\prime}-\mathrm{CH}_{2} \mathrm{OBz}$ and $\left.3^{\prime}-\mathrm{CH}_{2} \mathrm{OBz}\right), 3.20\left(1 \mathrm{H}, \mathrm{m}, \mathrm{H}-2^{\prime}\right), 2.62(1 \mathrm{H}$, m, H-4'a), 2.59 (1H, m, H-3'), 2.29 (1H, m, H-4'b); ${ }^{13} \mathrm{C}-\mathrm{NMR}$ $\left(100 \mathrm{MHz}, \quad \mathrm{CD}_{3} \mathrm{OD}\right) \quad \delta: 158.0,155.0,152.0,141.7,119.3$, 62.6, 61.6, 52.0, 47.3, 34.2, 29.7; HR-MS (ESI) Calcd for $\mathrm{C}_{11} \mathrm{H}_{14} \mathrm{ClN}_{5} \mathrm{NaO}_{2}[\mathrm{M}+\mathrm{Na}]^{+}:$306.07282. Found 306.07305; mp:
209.1-210.5 ${ }^{\circ} \mathrm{C}$.

2-Amino-6-chloro-9-(cis-3'-hydroxymethylcyclobutyl)purine (2c)

Yield 69\%; white crystals; ${ }^{1} \mathrm{H}-\mathrm{NMR}\left(400 \mathrm{MHz}, \mathrm{CD}_{3} \mathrm{OD}\right)$ $\delta: 8.22(1 \mathrm{H}, \mathrm{s}, \mathrm{H}-8), 4.90\left(1 \mathrm{H}, \mathrm{m}, \mathrm{H}-1^{\prime}\right), 3.67(2 \mathrm{H}, \mathrm{m}$, $\left.3^{\prime}-\mathrm{CH}_{2} \mathrm{OBz}\right), 2.66\left(2 \mathrm{H}, \mathrm{m}, \mathrm{H}-2^{\prime} \mathrm{a}\right.$ and $\left.\mathrm{H}-4^{\prime} \mathrm{a}\right), 2.44(3 \mathrm{H}, \mathrm{m}$, $\mathrm{H}-2^{\prime} \mathrm{b}, \mathrm{H}-3^{\prime}$ and $\left.\mathrm{H}-4^{\prime} \mathrm{b}\right) ;{ }^{13} \mathrm{C}-\mathrm{NMR}$ (100 MHz, CD $\left.\mathrm{CD}_{3} \mathrm{OD}\right) \delta$ : 158.0, 155.0, 151.9, 141.3, 119.2, 66.1, 46.8, 33.3, 31.7; HR-MS (ESI) Calcd for $\mathrm{C}_{10} \mathrm{H}_{12} \mathrm{ClN}_{5} \mathrm{NaO}[\mathrm{M}+\mathrm{Na}]^{+}$: 276.06226. Found 276.06236; mp: $152.3-153.4^{\circ} \mathrm{C}$.

2-Amino-6-chloro-9-(trans-3'-hydroxymethylcyclobutyl)purine (2d)

Yield 68\%; white crystals; ${ }^{1} \mathrm{H}-\mathrm{NMR}\left(400 \mathrm{MHz}, \mathrm{CD}_{3} \mathrm{OD}\right) \delta$ : 8.17 (1H, s, H-8), 5.00 (1H, m, H-1'), 3.64 (2H, m, 3'- $\left.\mathrm{CH}_{2} \mathrm{OBz}\right)$, 2.67 (2H, m, H-2'a and H-4'a), 2.52 (3H, m, H-2'b, H-3' and $\left.\mathrm{H}-4^{\prime} \mathrm{b}\right) ;{ }^{13} \mathrm{C}-\mathrm{NMR}\left(100 \mathrm{MHz}, \mathrm{CD}_{3} \mathrm{OD}\right) \delta$ : 158.0, 155.1, 151.9, 141.4, 119.3, 65.7, 48.6, 32.3, 32.1; HR-MS (ESI) Calcd for $\mathrm{C}_{10} \mathrm{H}_{12} \mathrm{ClN}_{5} \mathrm{NaO}[\mathrm{M}+\mathrm{Na}]^{+}:$276.06226. Found 276.06239; mp: $256.5-257.9^{\circ} \mathrm{C}$.

3,3-Bis(benzoyloxymethyl)-1-benzyloxycyclobutane

Compound 5 (2.48 g, $11.16 \mathrm{mmol})$ was dissolved in dry pyridine $(24.2 \mathrm{~mL})$, and benzoyl chloride $(2.72 \mathrm{~mL}, 23.44 \mathrm{mmol})$ was added dropwise to the solution at $0^{\circ} \mathrm{C}$, and the mixture was stirred for $2 \mathrm{~h}$ at room temperature. The mixture was then cooled to $0^{\circ} \mathrm{C}, 5.0 \mathrm{~mL}$ of water was added over $3 \mathrm{~min}$, and the mixture was stirred at room temperature for $1 \mathrm{~h}$. The solvent was removed in vacuo and the residue was extracted with AcOEt. The organic extracts were washed with water, saturated potassium carbonate solution and saturated sodium chloride solution, dried with sodium sulfate, and then evaporated. The residue was purified by silica gel column chromatography $(30 \%$ AcOEt in hexane) to give a colorless oil 6 (4.31 g, $10.04 \mathrm{mmol}, 90 \%) .{ }^{1} \mathrm{H}-\mathrm{NMR}\left(400 \mathrm{MHz}, \mathrm{CDCl}_{3}\right) \delta$ : 7.99-8.08 (4H, m, Bz), 7.52-7.58 (2H, m, Bz), 7.38-7.45 (4H, $\mathrm{m}, \mathrm{Bz}), 7.26-7.36(5 \mathrm{H}, \mathrm{m}, \mathrm{Bn}), 4.44\left(4 \mathrm{H}, \mathrm{s}, 3-\mathrm{CH}_{2} \mathrm{OBz} \times 2\right)$, $4.42(2 \mathrm{H}, \mathrm{s}, \mathrm{Bn}), 4.22$ (1H, m, H-1), $2.40(2 \mathrm{H}, \mathrm{m}, \mathrm{H}-2 \mathrm{a}$ and $\mathrm{H}-4 \mathrm{a}), 2.19$ (2H, m, H-2b and $\mathrm{H}-4 \mathrm{~b}) ;{ }^{13} \mathrm{C}-\mathrm{NMR}(100 \mathrm{MHz}$, $\left.\mathrm{CDCl}_{3}\right) \delta: 166.6,166.5,138.0,133.2,133.1,130.0,129.8,129.7$, $129.6,128.5,128.4,128.4,127.9,127.7,70.1,68.7,68.4,67.7$, 35.0, 34.7; HR-MS (ESI) Calcd for $\mathrm{C}_{27} \mathrm{H}_{26} \mathrm{NaO}_{5}^{+}[\mathrm{M}+\mathrm{Na}]^{+}$: 453.16725. Found 453.16578.

3,3-Bis(benzoyloxymethyl)cyclobutan-1-ol (7) To a solution of this compound $\mathbf{6}(4.18 \mathrm{~g}, 9.71 \mathrm{mmol})$ in methanol $(53.4 \mathrm{~mL})$ was added $10 \% \mathrm{Pd}$ on carbon $(3.24 \mathrm{~g})$. The reaction mixture was stirred at room temperature under $\mathrm{H}_{2}$ atmosphere ( $1 \mathrm{~atm})$ for $18 \mathrm{~h}$. The suspension was filtered through a pad of Celite. The filtrate was evaporated, and then the residue was purified by silica gel column chromatography $(60 \%$ AcOEt in hexane) to give a colorless oil 7 (3.01 g, $8.84 \mathrm{mmol}$, 91\%). ${ }^{1} \mathrm{H}-\mathrm{NMR} \quad\left(400 \mathrm{MHz}, \mathrm{CDCl}_{3}\right) \quad \delta: 8.008 .07 \quad(4 \mathrm{H}, \mathrm{m}$, $\mathrm{Bz}), 7.51-7.58(2 \mathrm{H}, \mathrm{m}, \mathrm{Bz}), 7.38-7.45(4 \mathrm{H}, \mathrm{m}, \mathrm{Bz}), 4.50(1 \mathrm{H}$, m, H-1), 4.47 (2H, s, 3- $\left.\underline{\mathrm{CH}}_{2} \mathrm{OBz}\right), 4.42\left(2 \mathrm{H}, \mathrm{s}, 3-\mathrm{CH}_{2} \mathrm{OBz}\right)$, 2.46 (2H, m, H-2a and H-4a), 2.10 (2H, m, H-2b and $\mathrm{H}-4 \mathrm{~b})$; ${ }^{13} \mathrm{C}-\mathrm{NMR}\left(100 \mathrm{MHz}, \mathrm{CDCl}_{3}\right) \quad \delta: 166.6,166.6,133.2,133.1$, 129.8, 129.7, 129.6, 129.6, 128.5, 128.4, 68.9, 67.6, 62.7, 37.6, 34.2; HR-MS (ESI) Calcd for $\mathrm{C}_{20} \mathrm{H}_{20} \mathrm{NaO}_{5}^{+}[\mathrm{M}+\mathrm{Na}]^{+}$: 363.12029. Found 363.11926.

2,6-Dichloro-9-[3',3'-bis(benzoyloxymethyl)cyclobutyl]purine (8) A solution of compound 7 (204.2 mg, $0.60 \mathrm{mmol})$, triphenylphosphine $(157.4 \mathrm{mg}, 0.60 \mathrm{mmol}), 2,6$-dichloropurine $(94.5 \mathrm{mg}, 0.50 \mathrm{mmol})$ and $\operatorname{TMAD}\left(N, N, N^{\prime}, N^{\prime}-\right.$ 
tetramethylazodicarboxamide, $103.3 \mathrm{mg}, 0.60 \mathrm{mmol}$ ) in $\mathrm{THF}$ $(5.0 \mathrm{~mL})$ was stirred at $50^{\circ} \mathrm{C}$. After $22 \mathrm{~h}$ stirring, the residual solution was purified by silica gel column chromatography (60\% AcOEt in hexane) to give as a colorless oil $8(192.0 \mathrm{mg}$, $0.38 \mathrm{mmol}, 75 \%) .{ }^{1} \mathrm{H}-\mathrm{NMR}\left(400 \mathrm{MHz}, \mathrm{CDCl}_{3}\right) \delta: 8.23(1 \mathrm{H}, \mathrm{s}$, $\mathrm{H}-8), 7.99-8.11$ (4H, m, Bz), 7.56-7.64 (2H, m, Bz), 7.41-7.51 $(4 \mathrm{H}, \mathrm{m}, \mathrm{Bz}), 5.27\left(1 \mathrm{H}, \mathrm{m}, \mathrm{H}-1^{\prime}\right), 4.64\left(2 \mathrm{H}, \mathrm{s}, 3^{\prime}-\mathrm{CH}_{2} \mathrm{OBz}\right)$, $4.63\left(2 \mathrm{H}, \mathrm{s}, 3^{\prime}-\mathrm{CH}_{2} \mathrm{OBz}\right), 2.93$ (2H, m, H-2'a and $\left.\mathrm{H}^{\prime} 4^{\prime} \mathrm{a}\right), 2.83$ $\left(2 \mathrm{H}, \mathrm{m}, \mathrm{H}-2^{\prime} \mathrm{b}\right.$ and $\left.\mathrm{H}-4^{\prime} \mathrm{b}\right) ;{ }^{13} \mathrm{C}-\mathrm{NMR}\left(100 \mathrm{MHz}, \mathrm{CDCl}_{3}\right) \delta$ : $166.5,166.3,152.9,152.0,144.1,133.5,133.5,129.7,129.6$, 128.6, 67.8, 66.4, 60.4, 36.8, 34.3; HR-MS (ESI) Calcd for $\mathrm{C}_{25} \mathrm{H}_{20} \mathrm{Cl}_{2} \mathrm{~N}_{4} \mathrm{NaO}_{2}[\mathrm{M}+\mathrm{Na}]^{+}$: 533.07538. Found 533.07375.

2-Amino-6-chloro-9-[3',3'-bis(hydroxymethyl)cyclobutyl]purine (2e) Compound 8 (192.0 $\mathrm{mg}, 0.38 \mathrm{mmol})$ was dissolved in $\mathrm{NH}_{3}(14.0 \mathrm{~mL}) / \mathrm{MeOH}(3.0 \mathrm{~mL})$, and then sealed and stirred for $4 \mathrm{~d}$ at $100^{\circ} \mathrm{C}$. The mixture was evaporated, and the residue was purified by silica gel column chromatography $\left(25 \% \mathrm{MeOH}\right.$ in $\left.\mathrm{CH}_{2} \mathrm{Cl}_{2}\right)$ to give $2 \mathrm{e}$ as white crystals $(53.7 \mathrm{mg}$, $0.19 \mathrm{mmol}, 50 \%) .{ }^{1} \mathrm{H}-\mathrm{NMR}\left(400 \mathrm{MHz}, \mathrm{DMSO}-d_{6}\right) \delta: 8.38(1 \mathrm{H}$, s, H-8), $7.80(1 \mathrm{H}$, br s, 6-NH $), 4.94\left(1 \mathrm{H}, \mathrm{m}, \mathrm{H}-1^{\prime}\right), 4.88(1 \mathrm{H}$, t, $\left.J=5.2 \mathrm{~Hz}, 3^{\prime}-\mathrm{CH}_{2} \mathrm{OH}\right), 4.78\left(1 \mathrm{H}, \mathrm{t}, J=5.2 \mathrm{~Hz}, 3^{\prime}-\mathrm{CH}_{2} \mathrm{OH}\right)$, $3.56\left(2 \mathrm{H}, \mathrm{d}, J=5.2 \mathrm{~Hz}, 3^{\prime}-\mathrm{CH}_{2} \mathrm{OH}\right), 3.49\left(2 \mathrm{H}, \mathrm{d}, J=5.2 \mathrm{~Hz}, 3^{\prime}-\right.$ $\left.\mathrm{CH}_{2} \mathrm{OH}\right), 2.47$ (2H, m, H-2'a and H-4'a), 2.39 (2H, m, H-2'b and H-4'b); ${ }^{13} \mathrm{C}-\mathrm{NMR}\left(100 \mathrm{MHz}, \mathrm{DMSO}-d_{6}\right) \delta$ : 156.8, 152.7, 150.3, 139.7, 118.0, 65.0, 64.1, 43.2, 33.0; HR-MS (ESI) Calcd for $\mathrm{C}_{11} \mathrm{H}_{14} \mathrm{ClN}_{5} \mathrm{NaO}_{2}[\mathrm{M}+\mathrm{Na}]^{+}$: 306.07282. Found 306.07166; mp: $239.6^{\circ} \mathrm{C}$.

6-Benzyloxyspiro[3.3]heptane-2,2-dicarboxylic Acid Diisopropyl Ester (9) Compound $5(2.06 \mathrm{~g}, 9.27 \mathrm{mmol})$ was dissolved in dry pyridine $(7.7 \mathrm{~mL})$ and cooled by an ice bath. $p$-Toluenesulfonyl chloride $(4.42 \mathrm{~g}, 23.17 \mathrm{mmol})$ was added in small portions to the cooled solution under stirring in a dry atmosphere. The mixture was left standing overnight. The precipitate was filtered off, the filtrate was carefully poured into water $(50 \mathrm{~mL})$, and the product was extracted with AcOEt. The extract was washed with $1 \mathrm{~N} \mathrm{HCl}$, water and saturated sodium chloride solution, dried with sodium sulfate, and then evaporated. The residue was purified by silica gel column chromatography $(40 \%$ AcOEt in hexane) to give the ditosylate as an oil (4.70 g, $8.81 \mathrm{mmol}, 95 \%)$.

Next, disopropylmalonate $(714.9 \mu \mathrm{L}, 3.76 \mathrm{mmol})$ was slowly added to a suspension of $\mathrm{NaH}(60 \%$ suspension in mineral oil) (106.9 mg, $4.17 \mathrm{mmol})$ in dry $N, N$-dimethylformamide (DMF) $(10.0 \mathrm{~mL})$ under stirring at such a rate that the temperature was maintained below $70^{\circ} \mathrm{C}$. The ditosylate $(1.00 \mathrm{~g}, 1.88 \mathrm{mmol})$ and KI $(31.5 \mathrm{mg}, 0.19 \mathrm{mmol})$ were added to the mixture in one portion. The mixture was then stirred at $140^{\circ} \mathrm{C}$ for $14 \mathrm{~h}$. Then, it was cooled, poured into saturated aqueous solution of ammonium chloride, and the product was extracted with AcOEt, washed with saturated aqueous sodium chloride solution, dried with sodium sulfate, and then evaporated. The residue was purified by silica gel column chromatography (25\% AcOEt in hexane) to give as a colorless oil $9(646.0 \mathrm{mg}$, $1.73 \mathrm{mmol}, 92 \%) .{ }^{1} \mathrm{H}-\mathrm{NMR}\left(400 \mathrm{MHz}, \mathrm{CDCl}_{3}\right) \quad \delta: 7.26-7.35$ $(5 \mathrm{H}, \mathrm{m}, \mathrm{Bn}), 5.03\left(2 \mathrm{H}\right.$, hept, $\left.J=6.0 \mathrm{~Hz},{ }^{i} \mathrm{Pr}\right), 4.37(2 \mathrm{H}, \mathrm{s}, \mathrm{Bn})$, $3.92(1 \mathrm{H}, \mathrm{m}, \mathrm{H}-6), 2.53(4 \mathrm{H}, \mathrm{s}, \mathrm{H}-1$ and $\mathrm{H}-3), 2.36(2 \mathrm{H}, \mathrm{m}$, $\mathrm{H}-5 \mathrm{a}$ and H-7a), 2.02 (2H, m, H-5b and H-7b), $1.22(12 \mathrm{H}, \mathrm{d}$, $\left.J=6.0 \mathrm{~Hz},{ }^{i} \mathrm{Pr}\right) ;{ }^{13} \mathrm{C}-\mathrm{NMR}\left(100 \mathrm{MHz}, \mathrm{CDCl}_{3}\right) \delta: 171.3,138.2$, 128.4, 127.8, 127.6, 70.0, 68.7, 68.2, 49.3, 43.0, 40.7, 30.4, 21.5; HR-MS (ESI) Calcd for $\mathrm{C}_{22} \mathrm{H}_{30} \mathrm{NaO}_{5}[\mathrm{M}+\mathrm{Na}]^{+}: 397.19855$. Found 397.19838.
6-Benzyloxy-2,2-bis(hydroxymethyl)spiro[3.3]heptane (10) A solution of compound $9(620.1 \mathrm{mg}, 1.66 \mathrm{mmol})$ in dry THF $(5.0 \mathrm{~mL})$ was added by drops to an ice-cooled suspension of lithium aluminum hydride $(103.9 \mathrm{mg}, 2.34 \mathrm{mmol})$ in dry THF $(10.0 \mathrm{~mL})$, and the mixture was stirred for $1 \mathrm{~h}$ at room temperature, then cooled. The solution was treated with AcOEt $(2.0 \mathrm{~mL})$ and water $(1.0 \mathrm{~mL})$ to give a gel. The solid was filtrated and washed successively with AcOEt $(100 \mathrm{~mL})$. The filtrate and washing were combined, and washed with saturated sodium chloride solution, dried with sodium sulfate, and then evaporated. The residue was purified by silica gel column chromatography $(20 \% \mathrm{MeOH}$ in AcOEt) to give as an oil 10 (149.6 mg, 0.56 mmol, 34\%). ${ }^{1} \mathrm{H}-\mathrm{NMR}(400 \mathrm{MHz}$, $\left.\mathrm{CDCl}_{3}\right) \delta: 7.24-7.36(5 \mathrm{H}, \mathrm{m}, \mathrm{Bn}), 4.37(2 \mathrm{H}, \mathrm{s}, \mathrm{Bn}), 3.94(1 \mathrm{H}$, m, H-6), $3.64\left(4 \mathrm{H}, \mathrm{s}, 2-\mathrm{CH}_{2} \mathrm{OH} \times 2\right), 2.32(2 \mathrm{H}, \mathrm{m}, \mathrm{H}-5 \mathrm{a}$ and H-7a), 2.02 (2H, m, H-5b and H-7b), 1.82 and 1.85 (4H, s, H-1 and $\mathrm{H}-3) ;{ }^{13} \mathrm{C}-\mathrm{NMR}\left(100 \mathrm{MHz}, \mathrm{CDCl}_{3}\right) \delta: 138.2,128.4,127.9$, 127.7, 70.1, 69.3, 68.7, 44.3, 39.6, 39.2, 38.8, 29.5; HRMS (ESI) Calcd for $\mathrm{C}_{16} \mathrm{H}_{22} \mathrm{NaO}_{3}[\mathrm{M}+\mathrm{Na}]^{+}$: 285.14612. Found 285.14612.

6-Benzyloxy-2,2-bis(benzoyloxymethyl)spiro[3.3]heptane (11) Compound $\mathbf{1 0}(151.3 \mathrm{mg}, 0.58 \mathrm{mmol})$ was dissolved in dry pyridine $(1.3 \mathrm{~mL})$, and benzoyl chloride $(200.0 \mu \mathrm{L}$, $1.73 \mathrm{mmol}$ ) was added dropwise to the solution at $0^{\circ} \mathrm{C}$, and the mixture was stirred for $3 \mathrm{~h}$ at room temperature. The mixture was then cooled to $0^{\circ} \mathrm{C}, 0.3 \mathrm{~mL}$ of water was added over $1 \mathrm{~min}$, and the mixture was stirred at room temperature for $30 \mathrm{~min}$. The solvent was removed in vacuo and the residue was extracted with AcOEt. The organic extracts were washed with water, saturated potassium carbonate solution and saturated sodium chloride solution, dried with sodium sulfate, and then evaporated. The residue was purified by silica gel column chromatography (30\% AcOEt in hexane) to give a colorless oil 11 (238.2 mg, 0.51 mmol, 87\%). ${ }^{1} \mathrm{H}-\mathrm{NMR}\left(400 \mathrm{MHz}, \mathrm{CDCl}_{3}\right) \delta$ : $8.02(4 \mathrm{H}, \mathrm{m}, \mathrm{Bz}), 7.55$ (2H, m, Bz), 7.42 (4H, m, Bz), 7.24-7.36 $(5 \mathrm{H}, \mathrm{m}, \mathrm{Bn}), 4.38,4.40$ and $4.41\left(6 \mathrm{H}, \mathrm{s}, 2-\mathrm{CH}_{2} \mathrm{OBz} \times 2\right.$ and Bn), 3.96 (1H, m, H-6), 2.43 (2H, m, H-5a and H-7a), 2.13 (4H, s, H-1 and H-3), 2.11 (2H, m, H-5b and $\mathrm{H}-7 \mathrm{~b}) ;{ }^{13} \mathrm{C}-\mathrm{NMR}$ $\left(100 \mathrm{MHz}, \mathrm{CDCl}_{3}\right) \delta: 166.6,138.2,133.1,130.0,129.6,128.4$, $128.4,127.8,127.6,70.1,68.5,68.0,67.9,44.2,39.6,38.8$, 37.3, 29.5; HR-MS (ESI) Calcd for $\mathrm{C}_{30} \mathrm{H}_{30} \mathrm{NaO}_{5}[\mathrm{M}+\mathrm{Na}]^{+}$: 493.19855. Found 493.19666.

2,2-Bis(benzoyloxymethyl)-6-hydroxyspiro[3.3]heptane (12) To a solution of this compound $11(194.7 \mathrm{mg}, 0.41 \mathrm{mmol})$ in methanol $(5.0 \mathrm{~mL})$ was added $10 \% \mathrm{Pd}$ on carbon $(136.8 \mathrm{mg})$. The reaction mixture was stirred at room temperature under $\mathrm{H}_{2}$ atmosphere $(1 \mathrm{~atm})$ for $10 \mathrm{~h}$. The suspension was filtered through a pad of Celite. The filtrate was evaporated, and then the residue was purified by silica gel column chromatography (60\% AcOEt in hexane) to give a colorless oil $12(112.8 \mathrm{mg}$, $0.30 \mathrm{mmol}, 72 \%) .{ }^{1} \mathrm{H}-\mathrm{NMR}\left(400 \mathrm{MHz}, \mathrm{CDCl}_{3}\right) \delta: 8.02(4 \mathrm{H}, \mathrm{m}$, $\mathrm{Bz}), 7.55(2 \mathrm{H}, \mathrm{m}, \mathrm{Bz}), 7.42(4 \mathrm{H}, \mathrm{m}, \mathrm{Bz}), 4.40$ and $4.41(6 \mathrm{H}, \mathrm{s}$, 2- $\mathrm{CH}_{2} \mathrm{OBz} \times 2$ and $\left.\mathrm{Bn}\right), 4.20(1 \mathrm{H}, \mathrm{m}, \mathrm{H}-6), 2.49(2 \mathrm{H}, \mathrm{m}, \mathrm{H}-5 \mathrm{a}$ and $\mathrm{H}-7 \mathrm{a}), 2.12$ and $2.14(4 \mathrm{H}, \mathrm{s}, \mathrm{H}-1$ and $\mathrm{H}-3), 2.02(2 \mathrm{H}, \mathrm{m}$, $\mathrm{H}-5 \mathrm{~b}$ and $\mathrm{H}-7 \mathrm{~b}) ;{ }^{13} \mathrm{C}-\mathrm{NMR}\left(100 \mathrm{MHz}, \mathrm{CDCl}_{3}\right) \delta$ : 166.6, 133.1, 130.0, 129.6, 128.4, 68.0, 62.8, 47.1, 39.4, 38.6, 37.3, 28.7; HR-MS (ESI) Calcd for $\mathrm{C}_{23} \mathrm{H}_{24} \mathrm{NaO}_{5}[\mathrm{M}+\mathrm{Na}]^{+}$: 403.15159 . Found 403.15044.

2,6-Dichloro-9-[2',2'-bis(benzoyloxymethyl)spiro[ $\left[3^{\prime} .3^{\prime}\right]-$ hept-6'-yl]purine (13) A solution of compound 12 (102.8 mg, $0.27 \mathrm{mmol})$, triphenylphosphine $(85.0 \mathrm{mg}, 0.32 \mathrm{mmol}), 2,6-\mathrm{di}-$ chloropurine $(61.3 \mathrm{mg}, 0.32 \mathrm{mmol}$ ) and DIAD (diisopropyl 
azodicarbosylate, $63.8 \mu \mathrm{L}, 0.32 \mathrm{mmol})$ in THF $(3.0 \mathrm{~mL})$ was stirred at $50^{\circ} \mathrm{C}$. After $20 \mathrm{~h}$ stirring, the residual solution was purified by silica gel column chromatography $(60 \%$ AcOEt in hexane) to give as a colorless oil $13(127.7 \mathrm{mg}, 0.23 \mathrm{mmol}$, $86 \%) .{ }^{1} \mathrm{H}-\mathrm{NMR}\left(400 \mathrm{MHz}, \mathrm{CDCl}_{3}\right) \delta: 8.15(1 \mathrm{H}, \mathrm{s}, \mathrm{H}-8), 8.04$ $(4 \mathrm{H}, \mathrm{m}, \mathrm{Bz}), 7.58(2 \mathrm{H}, \mathrm{m}, \mathrm{Bz}), 7.45(4 \mathrm{H}, \mathrm{m}, \mathrm{Bz}), 4.98(1 \mathrm{H}$, $\left.\mathrm{m}, \mathrm{H}-6^{\prime}\right), 4.46$ and $4.47\left(4 \mathrm{H}, \mathrm{s}, 2^{\prime}-\mathrm{CH}_{2} \mathrm{OBz} \times 2\right), 2.86(2 \mathrm{H}$, m, H-5'a and H-7'a), 2.73 (2H, m, H-5' $\overline{5^{\prime} \mathrm{b}}$ and $\left.\mathrm{H}^{\prime} 7^{\prime} \mathrm{b}\right), 2.29$ and $2.38\left(4 \mathrm{H}, \mathrm{s}, \mathrm{H}-1^{\prime}\right.$ and $\left.\mathrm{H}-3^{\prime}\right) ;{ }^{13} \mathrm{C}-\mathrm{NMR}\left(100 \mathrm{MHz}, \mathrm{CDCl}_{3}\right) \delta$ : $166.7,152.9,152.8,151.8,144.0,133.3,131.1,129.8,129.6$, 128.5, 128.4, 67.7, 53.4, 43.5, 38.9, 38.3, 37.4, 31.6; HR-MS (ESI) Calcd for $\mathrm{C}_{28} \mathrm{H}_{24} \mathrm{Cl}_{2} \mathrm{~N}_{4} \mathrm{NaO}_{4}[\mathrm{M}+\mathrm{Na}]^{+}$: 573.10668. Found 573.10532.

2-Amino-6-chloro-9-[2', 2'-bis(hydroxymethyl)spiro[3'.3']hept-6'-yl]purine (2f) Compound $13(122.6 \mathrm{mg}, 0.22 \mathrm{mmol})$ was dissolved in $\mathrm{NH}_{3}(14.0 \mathrm{~mL}) / \mathrm{MeOH}(3.0 \mathrm{~mL})$, and then sealed and stirred for $1 \mathrm{~d}$ at $100^{\circ} \mathrm{C}$. The mixture was evaporated, and the residue was purified by silica gel column chromatography $\left(25 \% \mathrm{MeOH}\right.$ in $\left.\mathrm{CH}_{2} \mathrm{Cl}_{2}\right)$ to give $\mathbf{2 f}$ as white crystals (50.3 mg, 0.15 mmol, 70\%). ${ }^{1} \mathrm{H}-\mathrm{NMR}\left(400 \mathrm{MHz}, \mathrm{DMSO}-d_{6}\right) \delta$ :

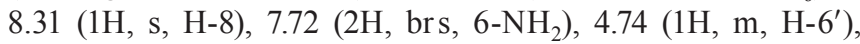
$4.47\left(2 \mathrm{H}, \mathrm{t}, J=5.6 \mathrm{~Hz}, 2^{\prime}-\mathrm{CH}_{2} \mathrm{OH} \times 2\right), 3.34(4 \mathrm{H}, \mathrm{t}, J=5.6 \mathrm{~Hz}$, $\left.2^{\prime}-\mathrm{CH}_{2} \mathrm{OH} \times 2\right), 2.48-2.60\left(4 \mathrm{H}, \overline{\mathrm{m}}, \mathrm{H}-5^{\prime}\right.$ and $\left.\mathrm{H}^{-} 7^{\prime}\right), 1.84$ and $1.96\left(4 \mathrm{H}, \mathrm{s}, \mathrm{H}-1^{\prime}\right.$ and $\left.\mathrm{H}-3^{\prime}\right) ;{ }^{13} \mathrm{C}-\mathrm{NMR}\left(100 \mathrm{MHz}, \mathrm{DMSO}-d_{6}\right)$ $\delta: 156.7,152.7,150.3,139.9,118.0,65.0,43.9,43.2,37.7,37.0$, 30.7; HR-MS (ESI) Calcd for $\mathrm{C}_{14} \mathrm{H}_{18} \mathrm{ClN}_{5} \mathrm{NaO}_{2} \quad[\mathrm{M}+\mathrm{Na}]^{+}$: 346.10412. Found 346.10258; mp: $233.8^{\circ} \mathrm{C}$.

Assay Angiogenesis Kit, Tubule Staining Kit for CD31, human umbilical vein endothelial cells (HUVEC), fetal bovine serum (FBS), vascular endothelial growth factor-A (VEGF), HuMedia EG2, and HuMedia EB2 were purchased from Kurabo Co. (Osaka, Japan). Cell Counting Kit 8 was supplied by Dojindo Molecular Technologies (Kumamoto, Japan).

Cell Culture A co-culture system of HUVEC and human fibroblasts (Angiogenesis Kit) was supplied in 24-well plates by Kurabo. ${ }^{4}$ Cells were incubated for $10 \mathrm{~d}$ prior to analysis with $450 \mu \mathrm{L}$ of the culture medium and a $50 \mu \mathrm{L}$ of saline that includes various additives. Culture medium was changed every $3 \mathrm{~d}$, each time including freshly prepared additives.

Tube Formation Assay Ten days following incubation periods with co-cultured fibroblasts and substrates (2a-f), HUVEC were stained using Tubule Staining Kit for CD31. ${ }^{4}$ The area of the formed tube was measured by the ImageJ program. Two pictures from each well were provided for the estimation. VEGF $(10 \mathrm{ng} / \mathrm{mL})$ was used as a positive control.

Proliferation Assay ${ }^{4}$ HUVECs were seeded on gelatincoated 96-well plates, typically at 3000 cells/well in $100 \mu \mathrm{L}$ of maintenance medium. After seeding, the plates were incubated for $24 \mathrm{~h}$ to permit anchorage, and then, the culture medium was changed with the assay medium, consisting of $90 \mu \mathrm{L}$ of HuMedia EB2 with $2 \%$ heat-inactivated FBS and $10 \mu \mathrm{L}$ of saline containing additives. The contents of HuMedia EB2 are almost identical to those of HuMedia EG2, except for the fact that the former does not include FBS, a growth factor, or antibiotics. The proliferation assay was performed using a Cell Counting Kit- $848 \mathrm{~h}$ after the addition of compounds $\mathbf{2 a}-\mathbf{f}$.

Statistics All experiments were performed at least 5 times. Mean values and standard error (S.E.) of the mean are shown. Statistical differences between groups were analyzed by Student's $t$-test and Dunnett's multiple comparison test using Microsoft Excel, and ANOVA followed by Scheffe's $F$ test using STAT VIEW II (Abacus Concepts). A $p$ value less than 0.05 was considered to be statistically significant.

Acknowledgment This research was partially supported by a Grant-in-Aid for Young Scientists (B), No. 24790123, from the Japan Society for the Promotion of Science (JSPS).

Conflict of Interest The authors declare no conflict of interest.

\section{References}

1) Bobek V., Taltynov O., Pinterova D., Kolostova K., Vascul. Pharmacol., 44, 395-405 (2006).

2) Collinson D. J., Donnelly R., Eur. J. Vasc. Endovasc. Surg., 28, 9-23 (2004).

3) O'Toole G., MacKenzie D., Buckley M. F., Lindeman R., Poole M., Br. J. Plast. Surg., 54, 1-7 (2001).

4) Tsukamoto I., Sakakibara N., Maruyama T., Igarashi J., Kosaka H., Kubota Y., Tokuda M., Ashino H., Hattori K., Tanaka S., Kawata M., Konishi R., Biochem. Biophys. Res. Commun., 399, 699-704 (2010).

5) Tsukamoto I., Konishi R., Tokuda M., Kubota Y., Maruyama T., Kosaka H., Igarashi J., PCT Int. Appl., WO 2010061931 A1 20100603 (2010).

6) Sakakibara N., Tsukamoto I., Tsurura T., Takata M., Konishi R., Maruyama T., Heterocycles, 85, 1105-1116 (2012).

7) Okabe N., Nakamura E., Himi N., Narita K., Tsukamoto I., Maruyama T., Sakakibara N., Nakamura T., Itano T., Miyamoto O., Brain Res., 1506, 115-131 (2013).

8) Mendelson K., Evans T., Hla T., Development, 141, 5-9 (2014).

9) Igarashi J., Hashimoto T., Kubota Y., Shoji K., Maruyama T., Sakakibara N., Takuwa Y., Ujihara Y., Katanosaka Y., Mohri S., Naruse K., Yamashita T., Okamoto R., Hirano K., Kosaka H., Takata M., Konishi R., Tsukamoto I., Pharmacology Research \& Perspectives, 2, e00068 (2014).

10) Biswas K., Yoshioka K., Asanuma K., Okamoto Y., Takuwa N., Sasaki T., Takuwa Y., J. Biol. Chem., 288, 2325-2339 (2013).

11) Igarashi J., Miyoshi M., Hashimoto T., Kubota Y., Kosaka H., Am. J. Physiol. Cell Physiol., 292, C740-C748 (2007).

12) Rikitake Y., Hirata K., Kawashima S., Ozaki M., Takahashi T., Ogawa W., Inoue N., Yokoyama M., Arterioscler. Thromb. Vasc. Biol., 22, 108-114 (2002).

13) Buzard D. J., Thatte J., Lerner M., Edwards J., Jones R. M., Expert Opinion Therapeutic Patents, 18, 1141-1159 (2008).

14) Crosignani S., Bombrun A., Covini D., Maio M., Marin D., Quattropani A., Swinnen D., Simpson D., Sauer W., Françon B., Martin T., Cambet Y., Nichols A., Martinou I., Burgat-Charvillon F., Rivron D., Donini C., Schott O., Eligert V., Novo-Perez L., Vitte P.-A., Arrighi J.-F., Bioorg. Med. Chem. Lett., 20, 1516-1519 (2010).

15) Shimizu H., Takahashi M., Kaneko T., Murakami T., Hakamata Y., Kudou S., Kishi T., Fukuchi K., Iwanami S., Kuriyama K., Yasue T., Enosawa S., Matsumoto K., Takeyoshi I., Morishita Y., Kobayashi E., Circulation, 111, 222-229 (2005).

16) Bolli M. H., Abele S., Binkert C., Bravo R., Buchmann S., Bur D., Gatfield J., Hess P., Kohl C., Mangold C., Mathys B., Menyhart K., Müller C., Nayler O., Scherz M., Schmidt G., Sippel V., Steiner B., Strasser D., Treiber A., Weller T., J. Med. Chem., 53, 4198-4211 (2010).

17) Matloubian M., Lo C. G., Cinamon G., Lesneski M. J., Xu Y., Brinkmann V., Allende M. L., Proia R. L., Cyster J. G., Nature (London), 427, 355-360 (2004).

18) Wei S. H., Rosen H., Matheu M. P., Sanna M. G., Wang S.-K., Jo E., Wong C.-H., Parker I., Cahalan M. D., Nat. Immunol., 6, 1228-1235 (2005).

19) Slusarchyk W. A., Young M. G., Bisacchi G. S., Hockstein D. R., 
Zahler R., Tetrahedron Lett., 30, 6453-6456 (1989).

20) Singh J., Bisacchi G. S., Ahmad S., Godfrey J. D. Jr., Kissick T. P., Mitt T., Kocy O., Vu T., Papaioannou C. G., Wong M. K., Heikes J. E., Zahler R., Mueller R. H., Org. Process Res. Dev., 2, 393-399 (1998).

21) Henlin J. M., Rink H., Spieser E., Baschang G., Helv. Chim. Acta, 75, 589-603 (1992).

22) Slusarchyk W. A., U.S. Patent, U.S. 5369098 A 19941129 (1994).

23) Tokunaga, T., Takasaki, T., Yoshida, K., Nagata, R., PCT Int. Appl., WO 2007032371 A1 20070322 (2007).

24) Bisacchi G. S., Braitman A., Cianci C. W., Clark J. M., Field A. K., Hagen M. E., Hockstein D. R., Malley M. F., Mitt T., Slusarchyk W. A., Sundeen J. E., Terry B. J., Tuomari A. V., Weaver E. R., Young
M. G., Zahler R., J. Med. Chem., 34, 1415-1421 (1991).

25) Sakakibara N., Hamasaki T., Baba M., Demizu Y., Kurihara M., Irie K., Iwai M., Asada E., Kato Y., Maruyama T., Bioorg. Med. Chem., 21, 5900-5906 (2013).

26) Maruyama T., Sato Y., Horii T., Shiota H., Nitta K., Shirasaka T., Mitsuya H., Honjo M., Chem. Pharm. Bull., 38, 2719-2725 (1990).

27) Radchenko D. S., Grygorenko O. O., Komarov I. V., Tetrahedron Asymmetry, 19, 2924-2930 (2008).

28) Yonesu K., Kawase Y., Inoue T., Takagi N., Tsuchida J., Takuwa Y., Kumakura S., Nara F., Biochem. Pharmacol., 77, 1011-1020 (2009).

29) Wong M. L. H., Prawira A., Kaye A. H., Hovens C. M., J. Clin. Neurosci., 16, 1119-1130 (2009). 